\title{
The effect of functional mandibular advancement for adolescent patients with skeletal class II malocclusion on the TMJ: a systematic review and meta-analysis
}

Lan Ding, Rui Chen, Jiaxin Liu, Yuan Wang, Qian Chang and Liling Ren*

\begin{abstract}
Objectives: This study aimed to assess whether functional mandibular advancement (FMA) will cause temporomandibular joint disorders (TMD) or have side effects on temporomandibular joint (TMJ) in adolescent patients.

Methods: All searched databases, including PubMed, Web of Science, EMBASE, Cochrane Central Register of Controlled Trails and Scopus were searched. Gray literature and unpublished literature was also searched. Randomized controlled trails (RCT) and non-randomized studies of the effects of interventions (NRSI) directly observe the condition of adolescent patients'TMJ after finishing treatment will be considered to include in our study. According to Cochrane Handbook, Cochrane Collaboration risk of bias tool was used to assess the quality of included RCTs, and Risk of Bias In Non-randomized Studies of Interventions (ROBINS-I) tool was used to assess the quality of included NRSIs.

Result: Finally 18 researches were evaluated as eligible to include in this study. 5 of the studies were RCTs, 8 were NRSIs and 5 were systematic reviews. The data of RCTs and NRSIs were statistically pooled in meta-analysis. The number of samples under investigated among primary studies was 579 individuals, there were 80 patients who developed temporomandibular symptoms during or after treatment. But all the subjective symptoms disappeared during followup time. The statistical outcomes proved that patients received FMA didn't show more tendency to develop temporomandibular symptoms $\left[1^{2}=27 \%, \mathrm{OR}=0.54,95 \% \mathrm{Cl}(0.33,0.87), \mathrm{p}=0.01\right]$.
\end{abstract}

Conclusion: (1) TMJ symptoms may occur during the functional oral appliance wearing, but the symptoms will release or disappear after treatment or during the follow-up period. (2) Less convincing evidence indicates that slightly previous TMD and condyle-glenoid fossa relationship will be improved after treatment. (3) There is TMJ disc anterior displacement observed during treatment, but most of them will return to the normal position later. (4) Moderate evidence support that FMA will not have side effects on TMJ of adolescent patients.

Keywords: Functional mandibular advancement, Temporomandibular joint disorders, Class II malocclusion, Orthodontics, Systematic review

\section{*Correspondence: renlil@|zu.edu.cn}

Department of Orthodontics, School of Stomology, Lanzhou University, No.199, Donggang West Road, Lanzhou City 730000, Gansu Province, China

\section{Introduction}

Skeletal class II malocclusion is regarded as a common disease among people [1-4], and its mechanism is either the overgrowing of maxillary, or the deficient of the mandibular [5]. For the second type, functional mandibular advancement (FMA) has become an effective 
treatment for skeletal class II malocclusion [6-8], and it is commonly used in adolescence who still have growing potential [9], usually cervical vertebral maturation stages (CVMS) I-IV [10], the age may range from 8 to 16 years, by having mandibular forward positioning to stimulate mandibular growing [11].

TMD is a disease that occurring in TMJ area and adjacent soft tissues, including muscle or TMJ pain to palpation, TMJ clicking, and the dysfunction of mandibular movement [12]. Often $40 \%-75 \%$ of the populations have at least one of TMD symptoms [13]. The reasons that caused TMD is complicated, and the factors consistently associated with TMD included other pain conditions (e.g. chronic headache) [14], sleep apnea, mental condition (e.g. anxiety, depression) [15], trauma [16, 17] and so on. Occlusion factors might be one of the main causes related to TMD [18]. TMD is categorized as intra-articular derangement (within the joint) and extra-articular derangement (involving the surrounding musculature) [17]. Articular disk displacement involving the disccondylar relationship is mostly common seeing in intraarticular dysfunction. Forward mandibular positioning will make the disc at a more advanced position, which might change the disc-condylar relationship and induce TMD. The impact of functional mandibular advancement on signs of temporomandibular dysfunction observed in previous published researches including TMJ capsular pain to palpation, TMJ sound, muscle pain to palpation $[6,19]$. And cone beam computed tomography $(\mathrm{CBCT})$ is also widely used to help diagnosing TMJ dysfunction [12, 20,21 ] by evaluating the morphology of condylar and whether the condylar position remains normally.

Although many researches in animals have proved there was no TMJ symptoms after functional mandibular advancement $[7,22]$, controversy still exists because of the adaption mechanism of the TMJ during functional mandibular advancement [23, 24]. Some researchers hold the opinion that functional mandibular advancement will have positive impact on TMJ reconstruction, which can help modifying better condyle-glenoid fossa relationship [25]. But on the contrary, others think that functional mandibular advancement might cause TMDs, since it breaks the balance of occlusal relationship [26-28]. However, the researches above were all based on clinical trials; the sample was not enough to offer convinced evidence, also, the potential bias from researchers selecting cases may affect their results. So, it seems that there was no high-quality evidence of existing literature regarding the impact of functional mandibular advancement on TMJ.

Some previous systematic reviews and meta-analyses published by Kurt Popowich [29] and Laura Ivorra-Carbonell [30] analyzed the morphology of TMJs after functional mandibular advancement, both of their researches found that the condyle was at a more advanced position, with the remodeling of the condyle and glenoid fossa; and no significant adverse effect was detected. But the results were inconclusive. Their evaluation of this problem was qualitative, which made the results less convinced. This systematic review and meta-analysis was undertaken to answer whether functional mandibular advancement would have adverse effects on TMJs in adolescence with quantitative measurement since no quantitative assessment was undertaken in previous researches.

\section{Objectives}

This systematic review and meta-analysis aims to evaluate whether functional mandibular advancement will cause temporomandibular joint disorders or have side effects on temporomandibular joint in adolescent patients.

\section{Materials and methods \\ Protocol and registration}

The protocol of this systematic review was developed and registered prospectively in PROSPERO (www.crd.york. ac.uk/prospero, CRD42020157906). This review was performed following the Cochrane Handbook for Systematic Reviews of Interventions [31]. The MOOSE guideline [32] and PRISMA statement [33] were followed by all of the authors to report the results.

\section{Eligibility criteria}

The following selection criteria were applied for this study.

1. Study design: randomized and controlled clinical trials, non-randomized studies of the effects of interventions, along with systematic review and metaanalysis, which considered the TMJ condition of patients after functional mandibular advancement with a period for observation.

2. Participants: adolescent patients who had received functional mandibular advancement.

3. Interventions: functional mandibular advancement appliance was used to improve profile and class II malocclusion.

4. Inclusion and exclusion criteria: Inclusion criteria: a. All controlled trials about the influence on TMJ caused by functional mandibular advancement; $\mathrm{b}$. Patients with good compliance till the end of treatment are of over $80 \%$ of the case number; c. Patients who didn't receive orthodontic treatment, orthognathic surgery, or TMD treatment before; $d$. The patients' age should be under 16 years; e. The studies are considered to be high quality or medium quality. Exclusion Criteria: a. Repeated researches; b. Stud- 
ies that didn't have control trials or before and after comparison; c. The patients whose age is over 16; $d$. The studies are considered to be of low quality by the criteria ordered by Cochrane Handbook for systematic reviews of interventions.

5. Outcome measures: we set 5 main indicators to assess the outcomes; they were the TMJ morphology before and after treatment, reported muscle disorders, position of TMJ disc before and after treatment, reported TMJ noises, reported Oral-facial pain and reported TMJ pain.

\section{Information sources, search strategy, and study selection}

International databases were used to find published articles from the opening of the database to August 2021. All searched databases, including PubMed, Web of Science, EMBASE, Cochrane Central Register of Controlled Trails and Scopus were thoroughly searched using keywords: mandibular advancement, mandibular forward positioning, functional mandibular advancement, Herbst appliance, activator appliance, bionator appliance, twin-block appliance, Fränkel appliance, Forsus appliance, temporomandibular joint, temporomandibular joint disease, craniofacial pain, condylar resorption, class II malocclusion, orthodontics, randomized clinical trial, controlled clinical trial, placebo, double-blinded method and single-blinded method (searching strategies are supported in Additional file 1). Also, gray literature was sought by hand search, and contacting the author to ask for the original text of meetings and conference abstract when needed.

Search evaluation and the assessment of risk of bias were made by 2 researches independently, and if there existed any dispute, the evaluation should be reevaluated by the third researcher. Original articles, case reports, case series, meetings and conference abstracts which are published in English are considered in this study. We also search for bibliographic survey to enhance the sensitivity and to select more articles. Unpublished literature was searched electronically in ClinicalTrials.gov (www.clini caltrials.gov) and the National Research Register (www. controlled-trials.com).

Full text or brief of all studies, reports, meeting or conference abstracts resulted from advanced search were extracted. After detailed screening the topic, abstract, and the full text, and removing the duplicates, so that the unrelated studies could be excluded and the related ones could be selected. The articles considered for this study including randomized controlled trails, non-randomized studies of the effects of interventions, and systematic reviews (the PRISMA flow diagram was reported in Additional file 2).

\section{Data items and collection}

For each RCT and NRSI, data were extracted based on topic, published year, type of study, total sample size, the ratio of gender, average age of patients, total amount of advancement, follow-up time, examination after finishing the treatment, outcome and result synthesis. All the data were performed in Table 1.

Table 1 basic characteristics of the included studies.

Outcome: a. TMJ morphology b. Muscle disorders c. Position of TMJ disc d. TMJ clicking e.Oral-facial pain f. TMJ pain to palpation.

\section{Risk of bias/quality assessment in individual studies}

After selection of the studies in terms of the topic, abstract and design of the experiment, to assess the quality of the selected studies, Cochrane Collaboration risk of bias tool [35] was used to assess the quality of included RCTs, and seven criteria were analyzed to grade the risk of bias inherent in each study, including random sequence generation, allocation concealment, blinding of participants and personnel, blinding of outcome assessment, incomplete outcome data, selective reporting and other potential source of bias. Studies with at least 1 criterion of high risk would be regarded as having a high risk of bias overall, and excluded from meta-analysis. Risk of Bias in Non-randomized Studies of the Effects of Interventions (ROBINS-I) tool was used to assess the quality of included non-randomized trials, also seven criteria were used to evaluate the inherent risk of bias in each study, including confounding, selection bias, classification of interventions, deviation from interventions, missing data, measurement of outcome, and selection of reported result. Studies with at least 1 criterion of high risk would be regarded as having a high risk of bias overall, and excluded from meta-analysis. According to the guide of Cochrane Handbook, systematic reviews are considered as high quality evidence and capable of including in systematic review.

\section{Summary measures and approach to synthesis}

Heterogeneity of the included studies was gauged by assessing the treatment protocol-follow-up year, gender ratio, publish year, treatment period and total amount of advancement. Statistical heterogeneity was assessed by a forest plot in conjunction with $95 \%$ confidence intervals. P value below 0.1 meant significant heterogeneity. Index among studies was determined, applying $\mathrm{Z}$ test and 
Ding et al. BMC Oral Health $\quad$ (2022) 22:51

Page 4 of 18

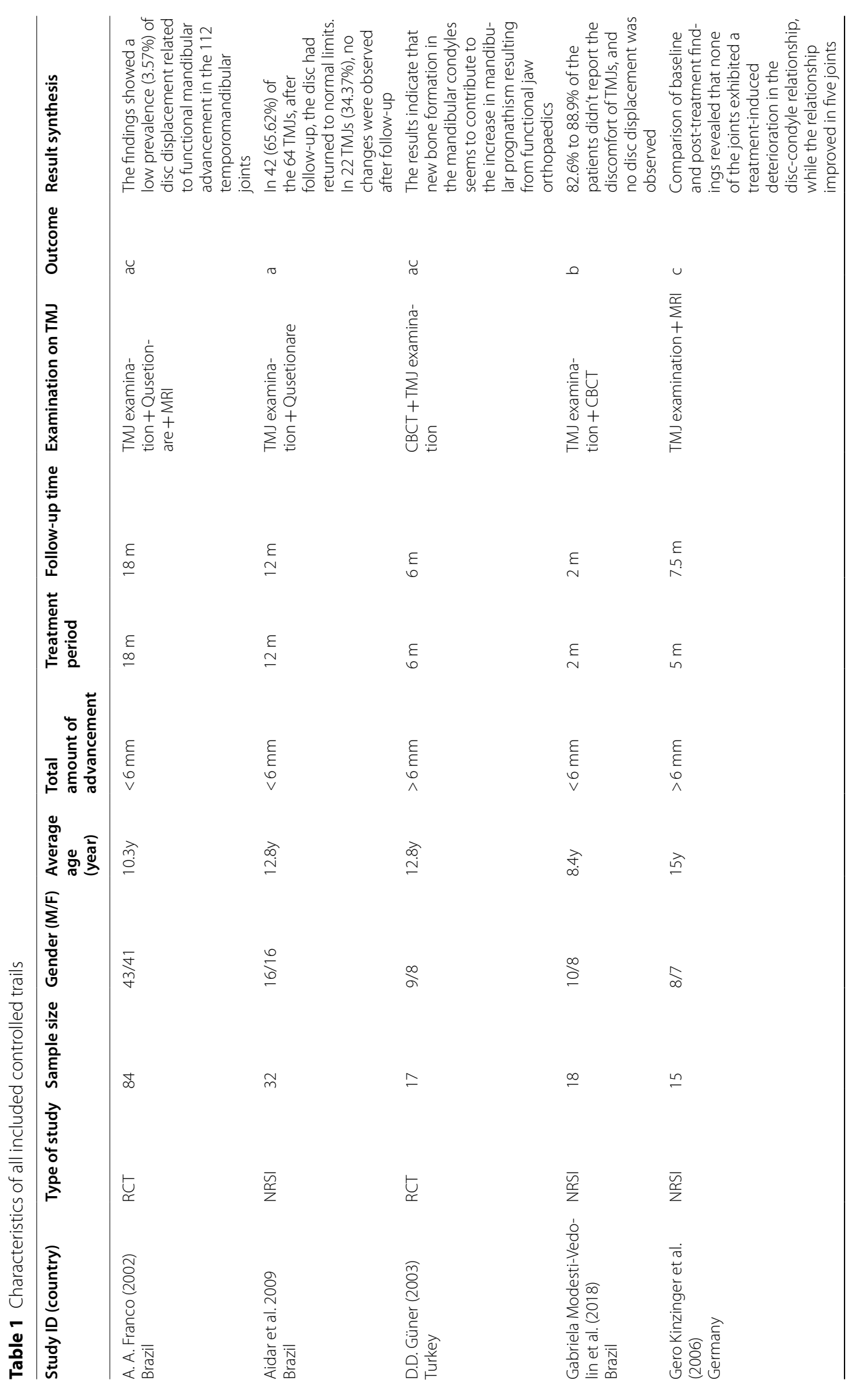




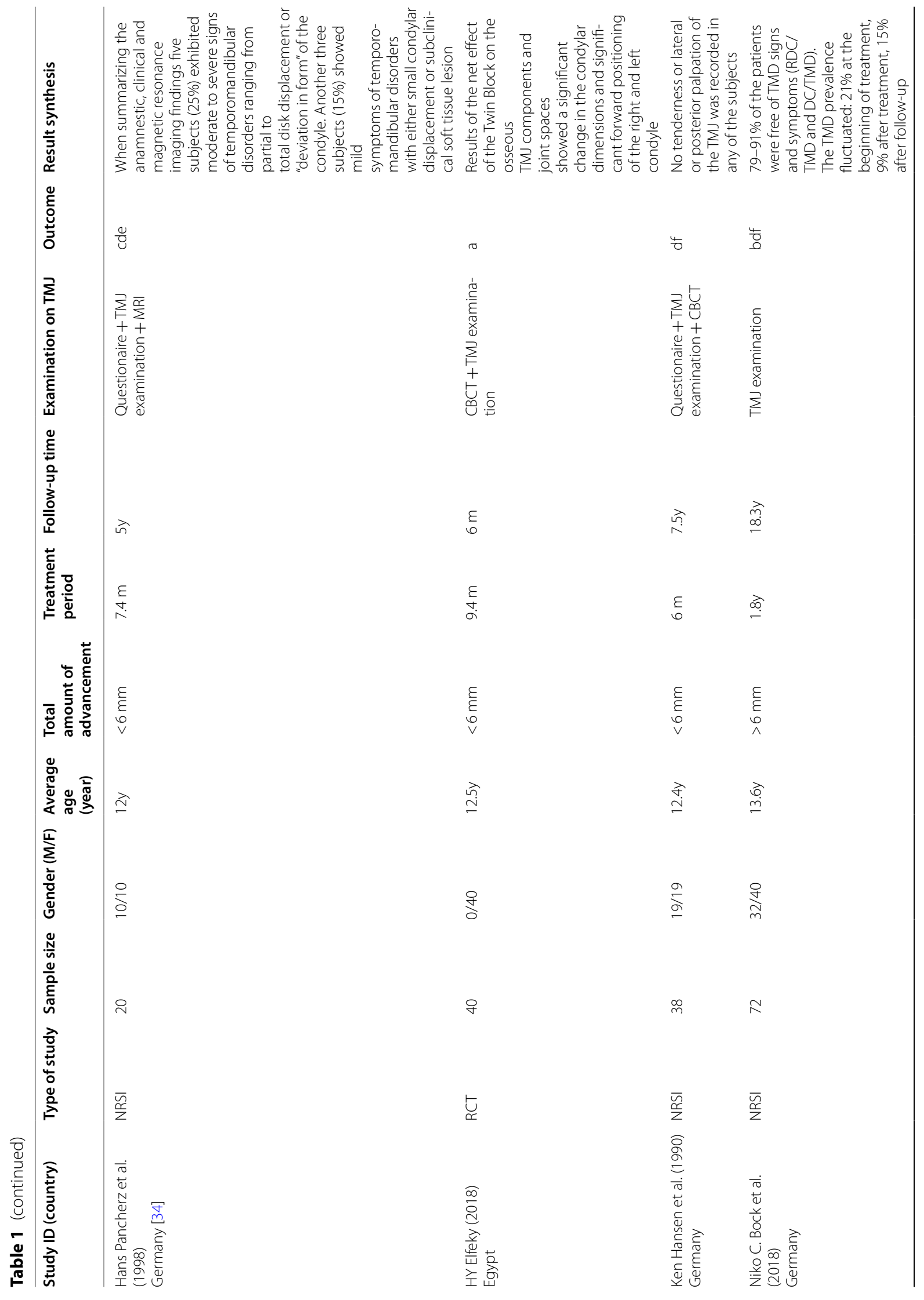




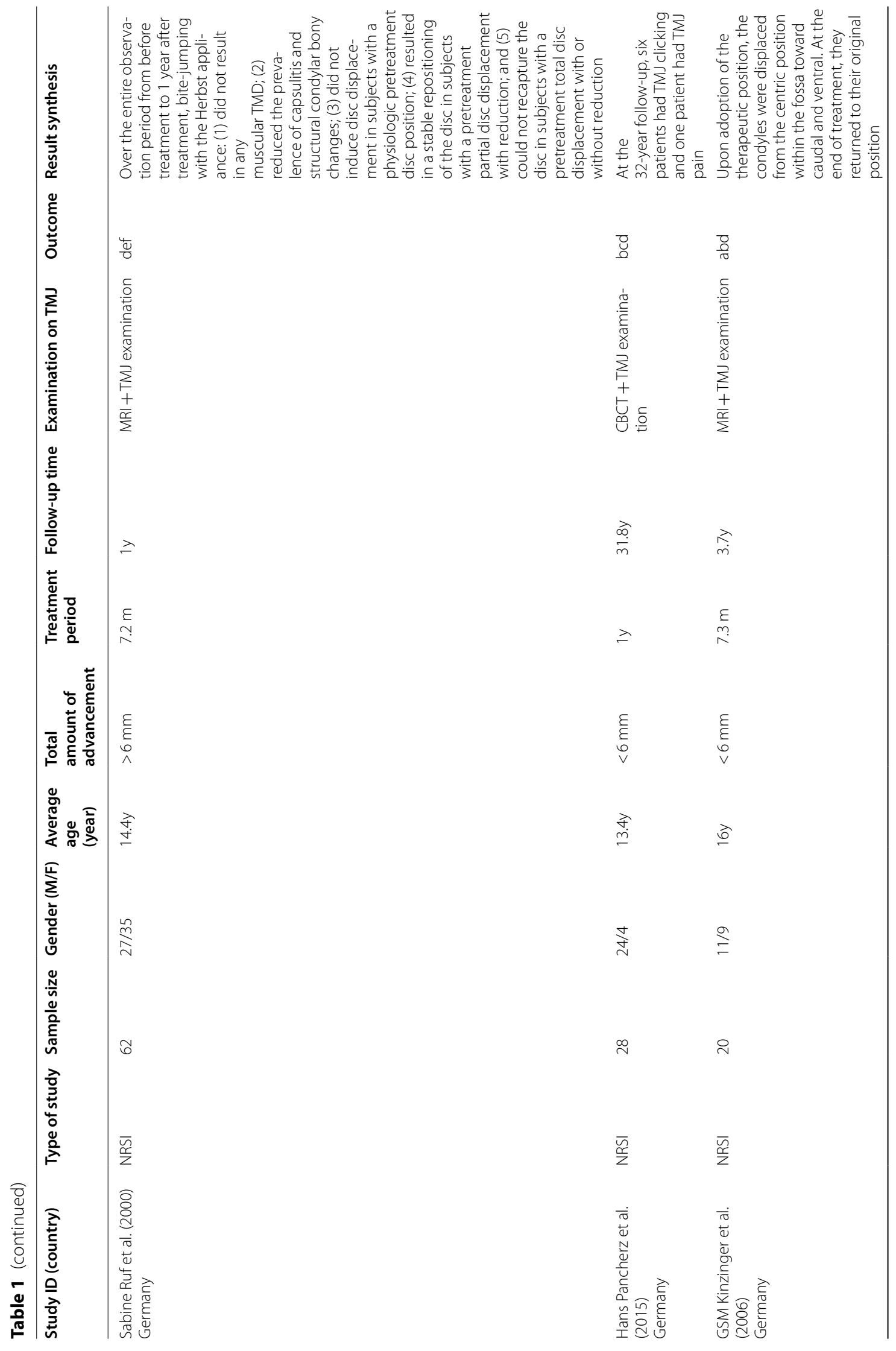




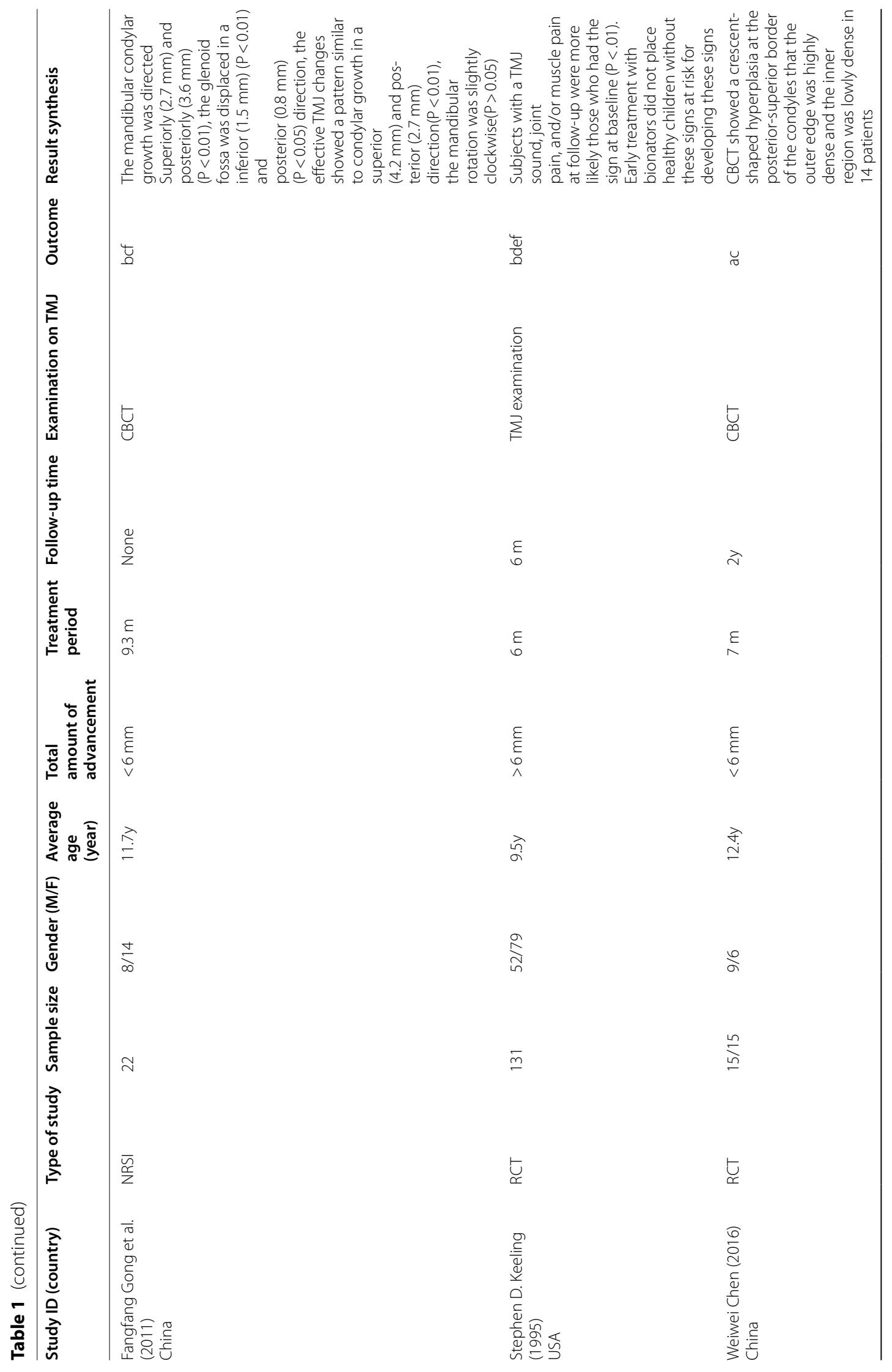




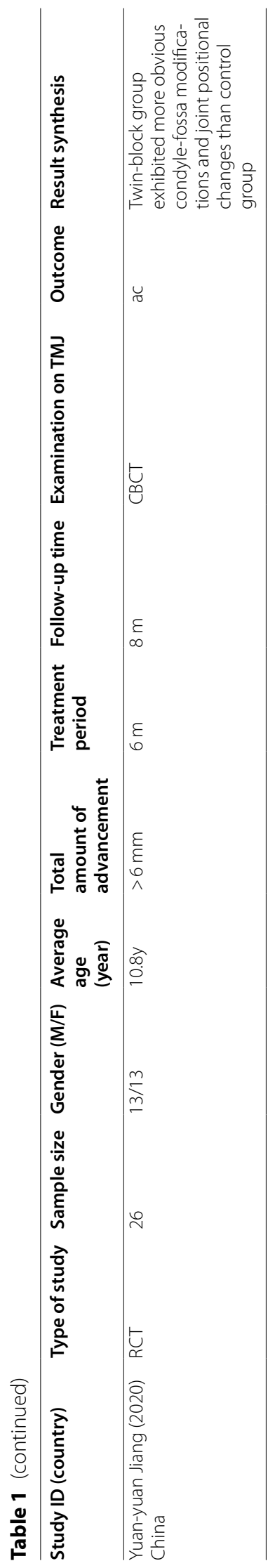


I-squared, according to heterogeneity results, random or fixed model was used for estimation. The results for developing TMD were expressed as odds ratios (OR).

\section{Risk of bias across studies}

Funnel plot was drawn to identify and evaluate publication bias.

\section{Additional analyses}

Sensitivity analysis was pooled to deal with studies with higher risk of bias. Publication bias, and other potential sources of heterogeneity including follow-up time, gender ratio, treatment period and total amount of advancement in included studies would be assessed by subgroup analyses. Meta-analysis, sensitivity analysis and subgroup analyses were undertaken using Review Manager Ver 5.3 software.

\section{Result}

\section{Study selection and characteristics}

A sensitive search including 1015 articles was found out. After reading the topic and abstract, 25 studies were selected in this study. And according to the exclusion criteria, 4 articles were excluded, so that 21 articles were included in this study finally. The flow of study selection is performed in PRISMA flow diagram (Additional file 2).

PRISMA flow diagram of article retrieval.

\section{Risk of bias within studies}

Seven criteria were pooled to analyze the inherent risk of bias of each included RCTs, including random sequence generation, allocation concealment, blinding of participants and personnel, blinding of outcome assessment, incomplete outcome data, selective reporting, and other potential sources of bias. The result of quality assessment was showed in Fig. 1. And an overview of author's judgments concerning all aspects of risk of bias is presented in Fig. 2. Also ROBINS-I tool was used to assess the quality of included NRSIs, seven criteria including confounding, selection bias, classification of interventions, deviation from interventions, missing data, measurement of outcome, and selection of reported result were used to analyze the risk of bias. The result was showed in Table 2. Additionally, all included studies declared that there was no selective reporting of results in their studies. Considering all the patients should be informed the orthodontic treatment plan, so we couldn't include any double-blinded methods. All authors stated in the literature that there was no attempt to blind the participants, but all the patients were not informed of others' treatment plan. In particular, our included articles mentioned blinding of all assessors.
Therefore, overall, 2 NRSIs and 1 RCT were deemed as low quality and they were not eligible for meta-analysis, other 13 studies were eligible to be pooled in quantitative assessment. According to Cochrane Handbook, systematic review is considered to offer strong evidence, so 5 systematic reviews were also included, and the conclusion would be stated in discussion of this study.

\section{Results of individual studies, meta-analysis, and additional analyses \\ Results of meta-analysis}

Review Manager Ver5.3 software was utilized to analyze data. Sensitivity analysis was also undertaken to determine effective studies in terms of heterogeneity. Funnel plot was performed to assess publication bias (Fig. 3), and the results showed that there was little publish bias among studies.

In this meta-analysis, we used OR as a statistical indicator, and the result showed in Fig. 4 that the degree of heterogeneity is significant $\left[\mathrm{I}^{2}=38 \%, \mathrm{OR}=0.61,95 \% \mathrm{CI}\right.$ $(0.37,0.99), \mathrm{P}=0.05]$. So that the random effects model was used to analyze the data. Meta-analysis performed that compared with pre-treatment, patients who received the intervention of functional mandibular advancement didn't appear to have more serious TMD or attain new TMJ symptoms, and the consequence had statistical significance.

Sensitivity analysis to examine role of each primary study in heterogeneity showed that research done by Stephen D. Keeling had the most effect on heterogeneity, and heterogeneity decreased evidently after removing this study $\left[\mathrm{I}^{2}=27 \%, \mathrm{OR}=0.54,95 \% \mathrm{CI}(0.33,0.87)\right.$, $\mathrm{p}=0.01]$. The result was performed in Fig. 5 .

\section{Results of included systematic reviews}

After electronic searching, finally 5 systematic reviews were included in this study because they were directly related to the review topic and met the selection criteria. The synthesis of results and conclusions was demonstrated in Table 3. And the results of these studies would be assessed in the following 3 aspects.

\section{Temporommandibular joint symptoms}

Few cases in the included studies reported temporomandibular joint symptoms (32 of 962, 3.3\%) during treatment time, but these temporary symptoms disappeared during follow-up time. The reported symptoms included TMJ noises, TMJ pain and oral facial pain, but no TMJ dysfunction.

\section{Condyle and glenoid fossa remodeling}

In the studies of Popowich K [36], Ivorra-Carbonell L [37], Santana LG [9] and Kyburz KS [38], treated samples 


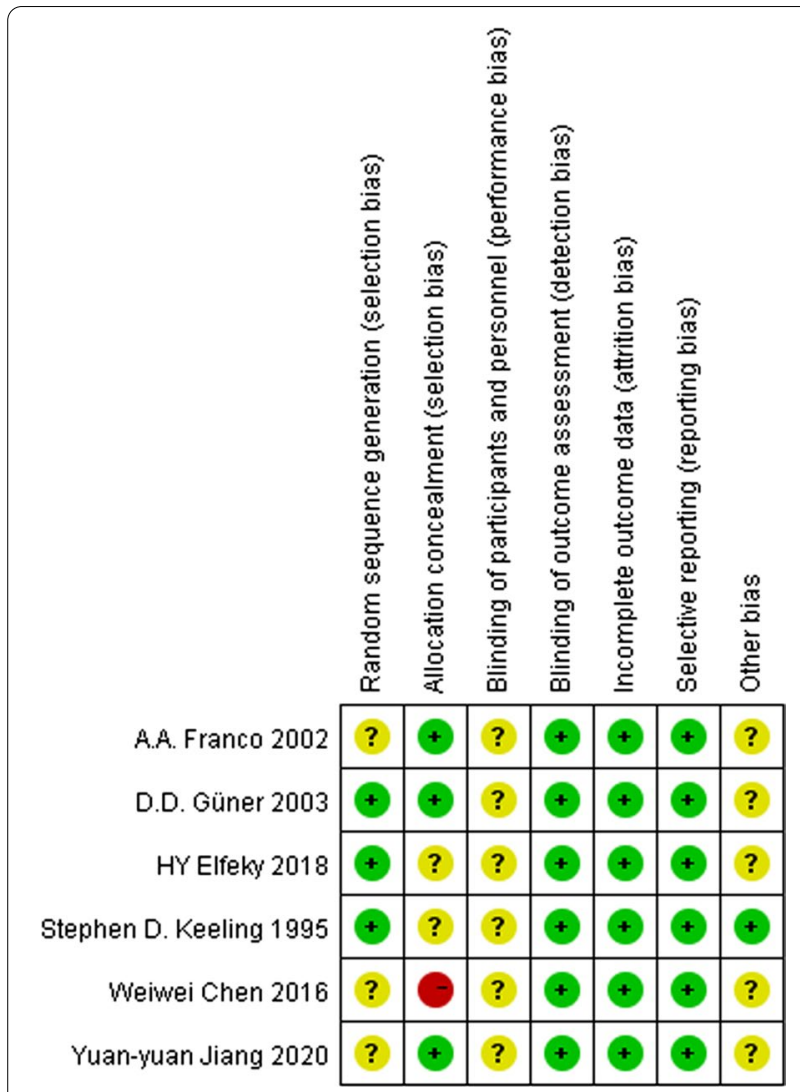

Fig. 1 Risk of bias summary

with permanent teeth were asked to take MRI before and after the removal of appliance to measure the mophology of TMJ region. Compared with pretreatment condition, both condyle and glenoid fossa remodeling was visually inspected through MRI, also an area of increased signal intensity in the posterior-superior region of the condyle was reported in the TMJs. Only 17 cases (1.8\%) reported "osteoarthritic changes or deviations in condyle form" after treatment, but none of the samples reported TMJ dysfunction, either.

\section{Condylar and TMJ disc position}

Xinqi Huang [39] stated in their study that after the treatment of twin-block appliance, the condylar posterior space increased whereas the condylar anterior space reduced. But they revealed that no significant change of both anterior and posterior space of condylar was observed after the treatment of Herbst appliance. Otherwise, Kurt Popowich [29], Santana LG [9] and Kyburz KS [38] all measured TMJ disc on MRI, they found that at the end of treatment, totally 47 patients (4.9\%) had disc displacement, but during the follow-up year for about 1 year, the disc all had normal position. To conclude, functional mandibular advancement enables forward movement of the condylar position, but after the remodeling of glenoid and condylar, the TMJ disc will eventually have normal position without dysfunction of TMJ.

\section{Subgroup analysis}

Demographic data were obtained, the included researches were mainly divided into 5 subgroups to find out the resource of heterogeneity according to follow-up year (over or under 1 year), treatment time (over or under 0.5 year), gender ratio $(\mathrm{M} / \mathrm{F}>1, \mathrm{M} / \mathrm{F}<1$ or $\mathrm{M} / \mathrm{F} \approx 1)$, total amount of advancement (less or more than $6 \mathrm{~mm}$ ) and publish year (before or after 2010), the result of subgroup analyses was performed in Fig. 6. The result suggested that subgroup 1 (follow-up year) had little influence on the generation of the heterogeneity. On the contrary,

\section{Random sequence generation (selection bias)}

Allocation concealment (selection bias)

Blinding of participants and personnel (performance bias)

Blinding of outcome assessment (detection bias)

Incomplete outcome data (attrition bias)

Selective reporting (reporting bias)

Other bias

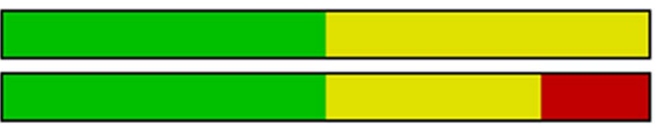

4

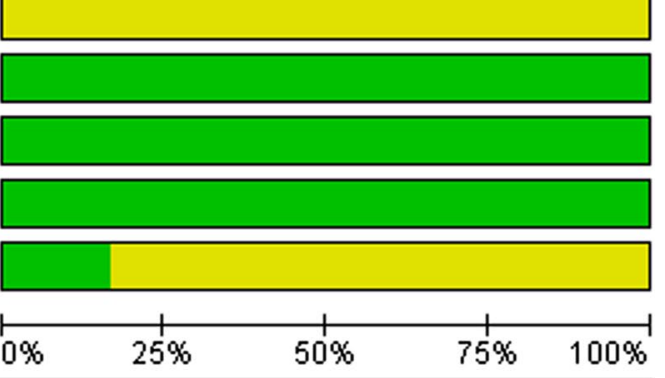

\begin{tabular}{|ll|}
\hline Low risk of bias $\quad \square$ Unclear risk of bias $\quad \square$ High risk of bias \\
\hline
\end{tabular}

Fig. 2 Risk of bias. Review author's judgments about each risk of bias item presented as percentage across all included studies 
Table 2 Bias assessment using the ROBINS-1 tool

\begin{tabular}{|c|c|c|c|c|c|c|c|}
\hline & Confounding & Selection bias & $\begin{array}{l}\text { Classification } \\
\text { of } \\
\text { interventions }\end{array}$ & $\begin{array}{l}\text { Deviation } \\
\text { from } \\
\text { interventions }\end{array}$ & Missing data & $\begin{array}{l}\text { Measurement } \\
\text { of outcome }\end{array}$ & $\begin{array}{l}\text { Selection } \\
\text { of reported } \\
\text { result }\end{array}$ \\
\hline Aidar et al. (2009) & Low risk & Moderate risk & Moderate risk & Low risk & Low risk & Low risk & Low risk \\
\hline Gabriela Modesti-Vedolin et al. & Low risk & Moderate risk & Low risk & Moderate risk & Low risk & Low risk & Low risk \\
\hline Gero Kinzinger et al. & Low risk & Low risk & Moderate risk & Low risk & Moderate risk & Low risk & Low risk \\
\hline Hans Pancherz et al. (1998) & Moderate risk & Low risk & Moderate risk & Moderate risk & Low risk & Low risk & Low risk \\
\hline Ken Hansen et al. (1990) & Moderate risk & Low risk & Moderate risk & Low risk & Low risk & Low risk & Low risk \\
\hline Niko C. Bock et al. (2018) & Moderate risk & Low risk & Low risk & Low risk & Low risk & Low risk & Moderate risk \\
\hline Sabine Ruf et al. (2000) & Low risk & Moderate risk & Moderate risk & Low risk & Low risk & Low risk & Low risk \\
\hline Hans Pancherz et al. (2015) & Low risk & Low risk & Moderate risk & Low risk & Low risk & Low risk & Moderate risk \\
\hline GSM Kinzinger et al. (2006) & High risk & Moderare risk & High risk & Low risk & Low risk & Low risk & Low risk \\
\hline Fangfang Gong et al. (2011) & High risk & High risk & Moderate risk & Low risk & Low risk & Low risk & Moderate risk \\
\hline
\end{tabular}

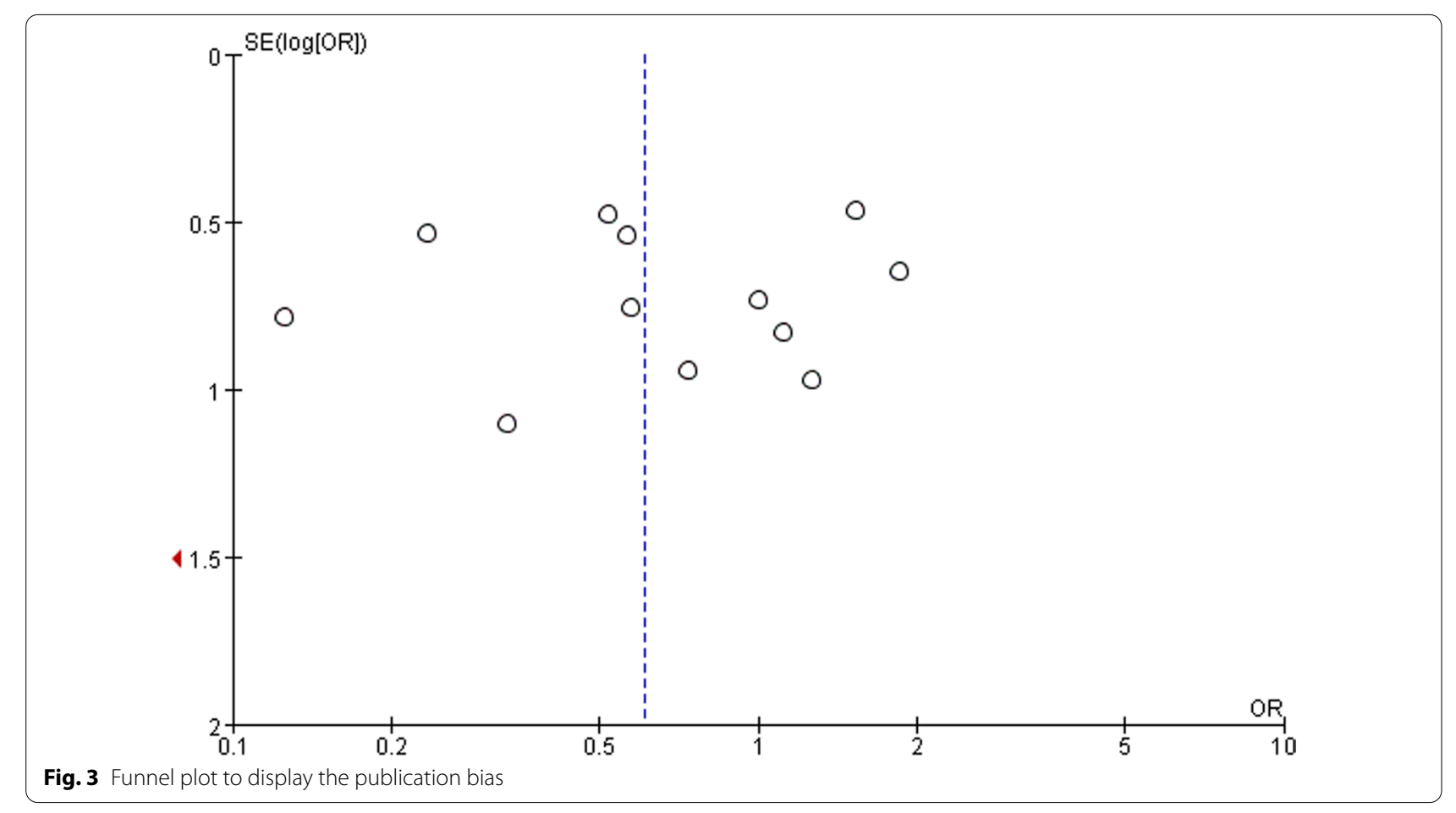

after subgroup analysis, $\mathrm{I}^{2}$ in subgroup $2-5$ had decreased to $0 \%$, which illustrated that these factors (gender ratio, treatment time, total amount of advancement and publish year)could be regarded as the chief resources of heterogeneity in this study. Further demonstration would be required in discussion.

\section{Discussion}

Summary of evidence

For this systematic review and meta-analysis, we evaluated the correlation between TMD and functional mandibular advancement. Following thorough database searches, it was observed that available researches were rare to obtain. Finally, 18 literatures were included in this systematic review. The quality of selected studies was able to answer this clinical question submitted in this systematic review. According to the criteria of 


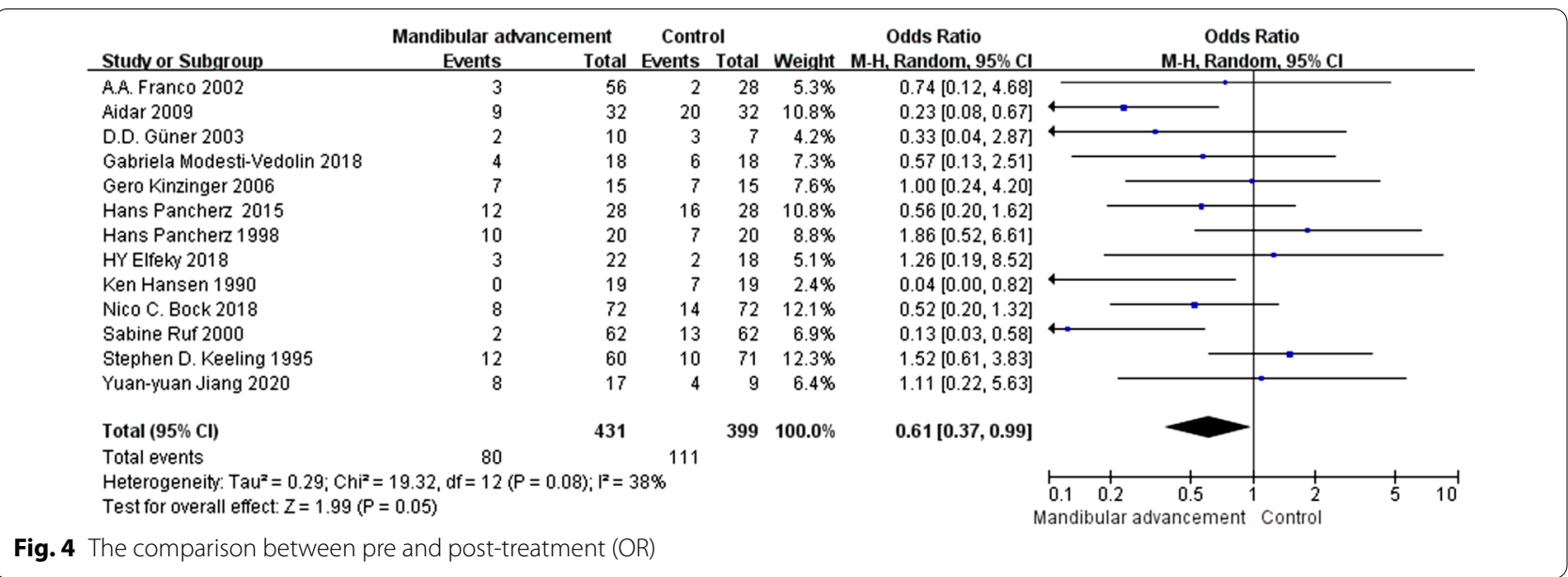

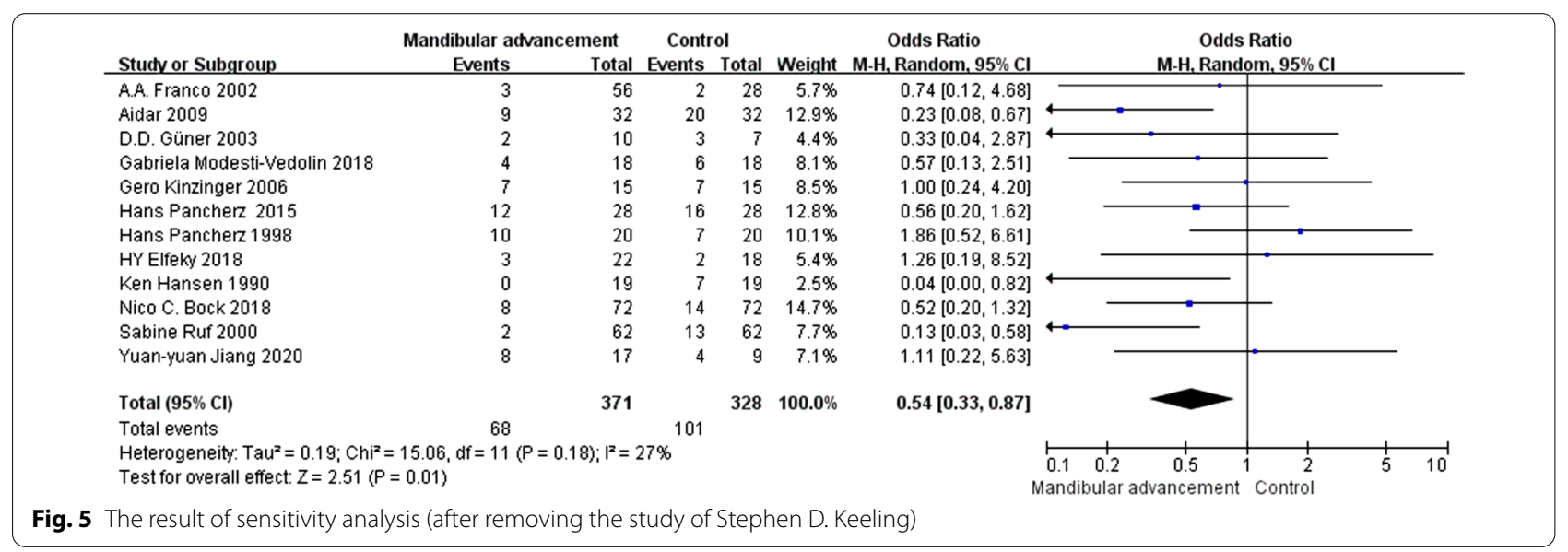

Table 3 The synthesis of results and conclusions of included systematic reviews

\begin{tabular}{|c|c|c|}
\hline Study ID & Country & Results/conclusion \\
\hline Kurt Popowich et al. (2002) & Canada & $\begin{array}{l}\text { The MRI studies did not provide conclusive evidence of osseous remodeling or condyle position } \\
\text { change. The tomography study demonstrated minor condyle position change. Methodological defi- } \\
\text { ciencies prevented major conclusions regarding disc position }\end{array}$ \\
\hline Laura Ivorra-Carbonell et al. (2016) & Spain & $\begin{array}{l}\text { After treatment with functional appliances, the condyle was found to be in a more advanced position, } \\
\text { with remodeling of the condyle and adaptation of the morphology of the glenoid fossa. No signifi- } \\
\text { cant adverse effects on the TMJ were observed in healthy patients and the appliances could improve } \\
\text { joints that initially presented forward dislocation of the disk }\end{array}$ \\
\hline Lucas Garcia Santana et al. (2020) & Brazil & $\begin{array}{l}\text { Low to very low certainty of evidence indicated that incremental mandibular advancement resulted } \\
\text { in greater gains in mandibular length }(\mathrm{MD}=0.89[0.38,1.34], \mathrm{p}=0.0005) \text {, anterior mandibular displace- } \\
\text { ment }(\mathrm{MD}=0.73[0.40,1.06], \mathrm{p}<0.001) \text { and } \mathrm{SNB} \text { angle }(\mathrm{MD}=0.44[0.02,0.85], \mathrm{p}<0.04)\end{array}$ \\
\hline Karma Shiba Kyburz et al. (2019) & Switzerland & $\begin{array}{l}\text { Currently existing evidence from controlled clinical studies on humans indicates that functional appli- } \\
\text { ance treatment is associated with positional and skeletal alterations of the temporomandibular joint } \\
\text { in the short term compared to untreated controls }\end{array}$ \\
\hline Xinqi Huang et al. (2016) & China & $\begin{array}{l}\text { The condylar position showed no changes after Herbst treatment. The condylar posterior space after } \\
\text { Twin-block treatment averagely increased by } 0.31 \mathrm{~mm}(P<0.00001) \text {, whereas the condylar anterior } \\
\text { space averagely reduced by } 0.32 \mathrm{~mm}(\mathrm{P}<0.00001) \text {. Twin-block appliance enables forward movement } \\
\text { of the condylar position }\end{array}$ \\
\hline
\end{tabular}


(A)

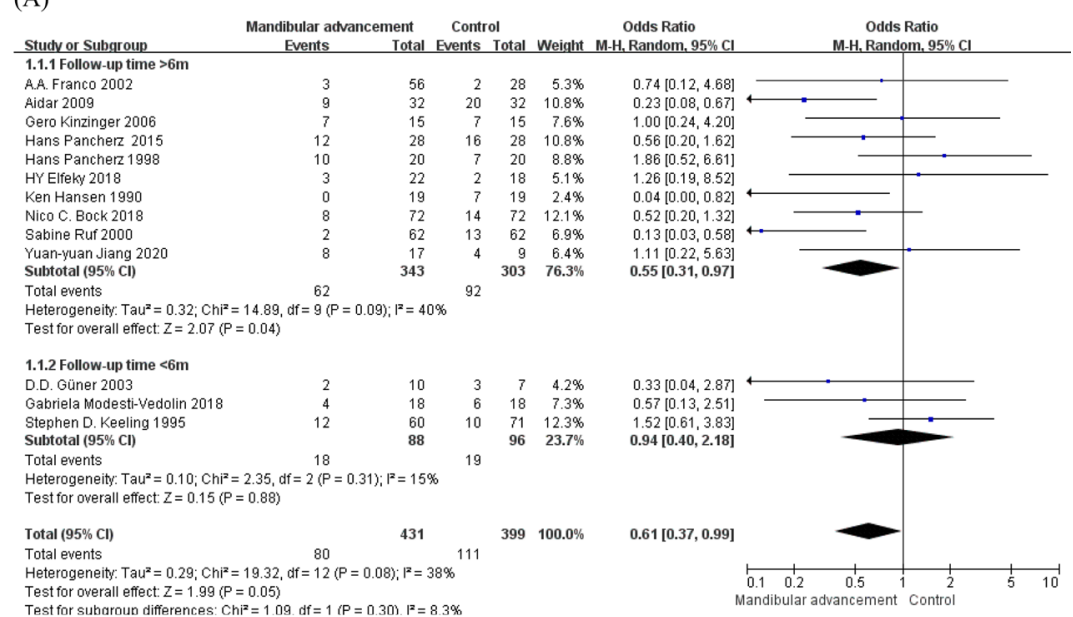

(B)

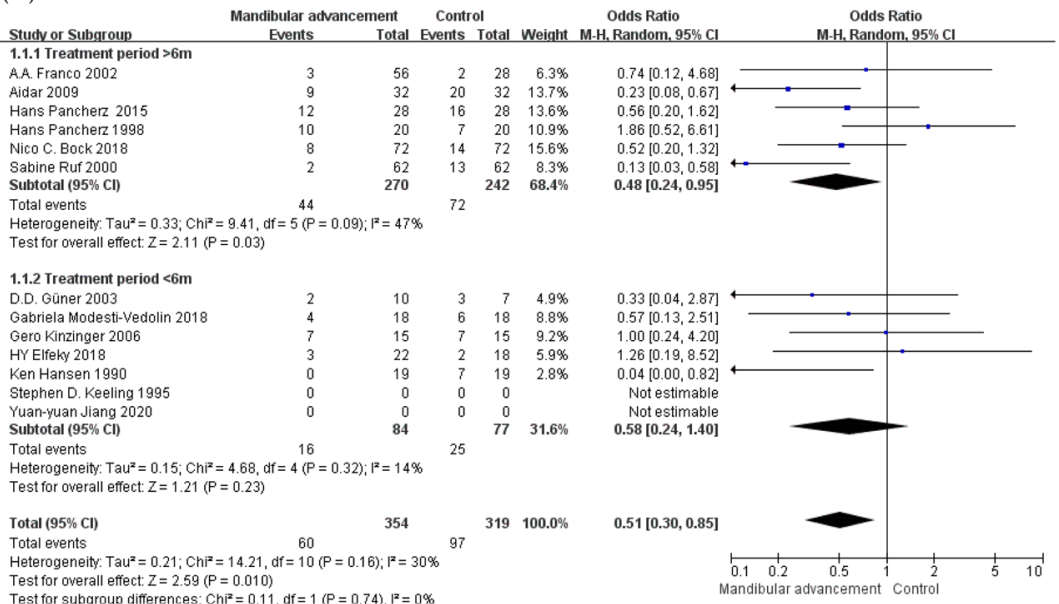

(C)

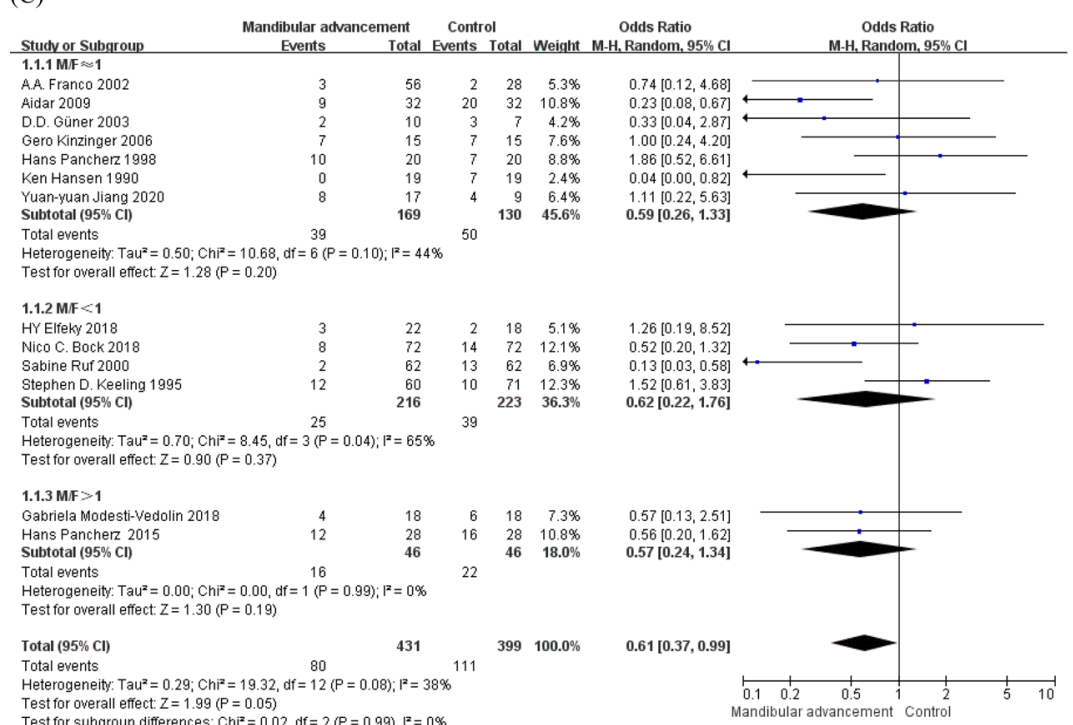

Fig. 6 The result of subgroup analysis $(\mathbf{a}-\mathbf{e})$ 


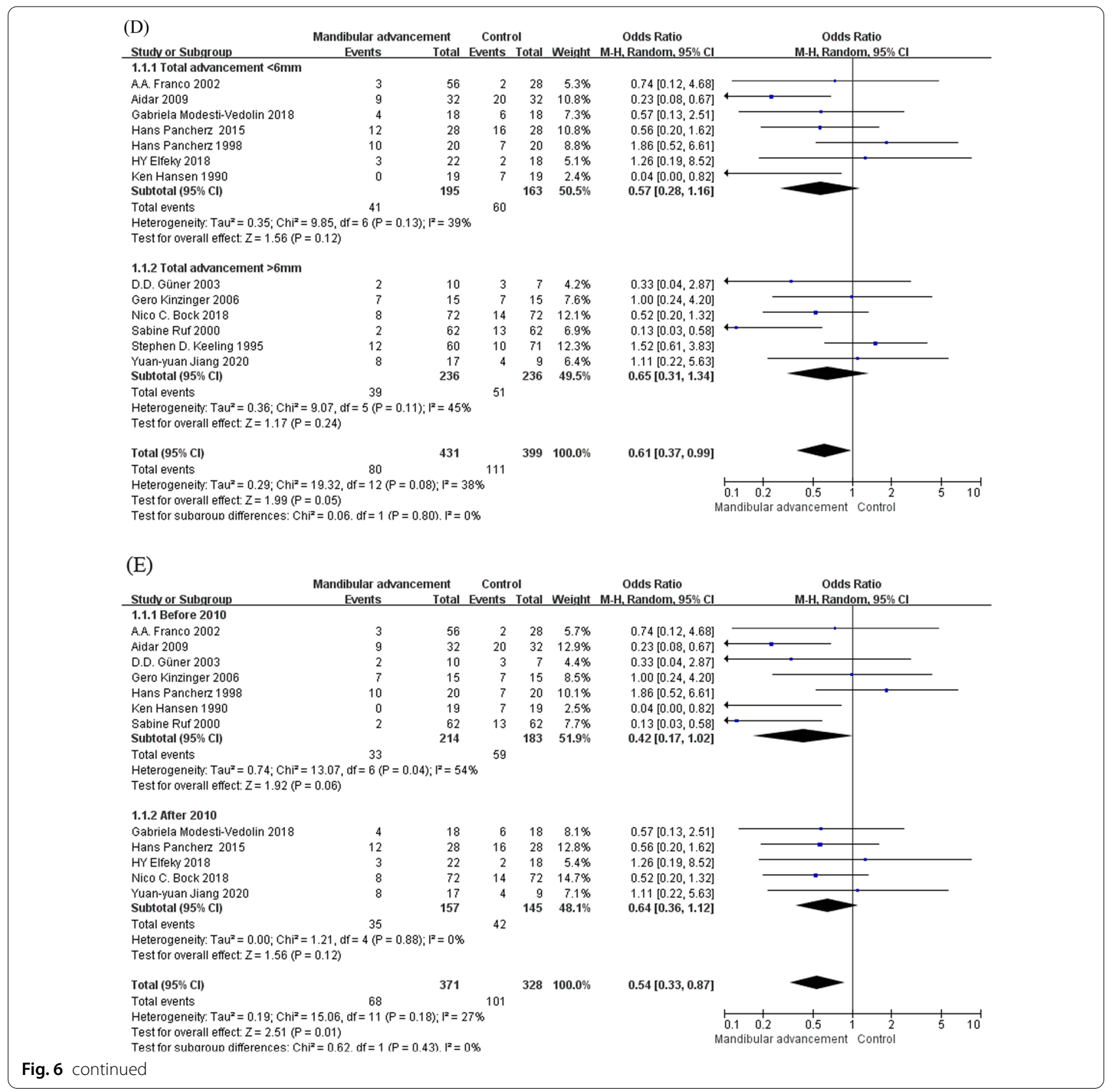

grading evidence given by Cochrane Handbook, our study included 5 systematic reviews, 5 RCTs and 8 NRSIs. After quantitative assessment of meta-analysis, our study indicated that functional mandibular advancement would not cause TMD $(\mathrm{P}<0.05)$.

Most of researches showed that after treatment, position of the condyle was more forward and glenoid fossa also remodeled, even in the patients who have anterior disc displacement with reduction (ADDR) [40], treatment-induced deterioration was not found in the disc-condyle relationship compared with pre-treatment condition, while the relationship was improved in some cases. The research published by Payam Owtad et al. [41] found that mandibular advancement could increase FGF8 factor in the TMJ region, which might promote adaptive remodeling of the TMJ disc, glenoid fossa and condyle, but it would cost a relatively long time to finish. Published researches had also reported some biochemical effects of functional mandibular advancement devices on the TMJ, even if the condyle was migrated to a more anterior position, no considerable stress was investigated on the TMJ structure [11, 29, 41, 42], but there 
was increasing pressure detected in masticatory muscle $[43,44]$. Many researchers also found that adolescence appeared to have more active reconstruction in the TMJ region than adults $[45,46]$, so this might indicate that muscle pain and TMJ discomfort could release in a relatively short period in adolescent patients, especially in who still had growing potential.

As stated before in subgroup analyses, some other factors besides the intervention method could also affect the result. Follow-up time after treatment was regarded as one of the main factors. After categorization of the included case reports according to follow-up period (short-term and long-term), seven pieces of research set over 1-year follow-up in their experiment, and the outcomes showed that these patients' TMJ morphology were as normal individuals, as well as no adverse effects were observed, also they didn't show more tendency to develop TMD; the other pieces of research which observed patients just several months found that nearly $20 \%$ of the patients reported TMJ symptoms (including TMJ clicking and masticatory muscle pain). Many researchers [47, 48] reported patients who received such treatment were more likely to have their temporomandibular joint disc at a more forward position. Paula Loureiro Cheib et al's research [43] also indicated that immediately after functional appliance, the condyles were displaced anteriorly and inferiorly. The systematic review published by Kurt Popowich [29] also offered high-quality evidence to support the idea that although few patients had their TMJ disc position changed, such changes might cause TMJ discomfort momentarily. But after a period for TMJ to adapt, subjective symptoms and clinical signs seemed to disappear, and no obvious dysfunction was observed in TMJ. TMD is a type of self-limiting disease; existing research had also already reported that usually after 12 weeks of clinical observation, there was no discomfort complained by patients with disc displacement [21]. So on the bias of different follow-up time in each research and the outcome indicators we set in this research (mainly subjective symptoms), the result might vary a lot. But no considerable stress was detected on the TMJ structure when the condyle was migrated to a more anterior position overall [22, 44, 49], even in the patients complained about TMJ symptoms. Since TMJ discomfort after mandibular advancement devices wearing might be related to muscle dysfunction rather than pressure on TMJ itself [2, 27], and the function of masticatory muscle would recovery after a period of time, although bias and heterogeneity existed in this research, the overall statistical result still showed that there was no adverse side effect on TMJs after functional mandibular advancement.

\section{The correlation between gender and TMD}

Gender can also be considered as a major factor that might affect the result. The studies published by Sabine Ruf [50], Niko C. Bock [51], HY Elfeky and Ken Hansen [42] all had bias on selecting samples, especially Ken Hansen's study, their samples were all males and the sample HY Elfeky selected were all female. As Bueno $\mathrm{CH}$ et al. [53] stated in their systematic review that compared to men, the risk that women developed TMD was two times greater. So did Sójka A et al.s observational research [54] on medical students in found that about one-third of the students in this study presented symptoms of TMD, and female students appeared to have a higher level of these symptoms. Tae-Yoon Kim et al. [55] gave evidence in their research that there may be physiological and pathological gender differences in TMD. There were more males in included samples than females in our study, since it already has evidence that women are more likely to have TMD, it might attribute to a bias in the final result.

\section{The correlation between total amount of advancement and TMD}

Furthermore, to assess the relevant influence that total amount of advancement had on TMJs, we compared patients who received over or less than $6 \mathrm{~mm}$ total advancement and designed a subgroup. It had statistical significance in our research that over $6 \mathrm{~mm}$ advancement would not cause TMD after treatment. Knappe SW [56] and his colleagues compared these two groups in their study, during a long period of follow-up for 2 years, they observed a great amount of total mandibular advancement would not make patients have higher a risk to cause TMDs.

\section{The correlation between treatment period and having TMJ subjective symptoms}

We also found that treatment time for functional appliance use would affect the outcomes, too. More patients underwent over 0.5 year treatment period complaining about TMJ symptoms than those who underwent treatment period less than 0.5 year. During treatment, the patient's mandible was positioned more forward, and the condylar also migrated anteriorly, too [22]. Stress on the temporomandibular joint structures considerably increased, so it might lead to TMJ symptoms report. As the treatment time prolonged, minor functional disturbances in the masticatory system appeared $[6,57]$. But these disturbances were temporary [58], the symptoms would finally disappear when the remodeling of condylar finished. 


\section{The effect that existing TMD having on outcomes}

Besides, patients with or without TMD before treatment will also affect the result. Peltola J S [27] took radiographic examination during follow-up time, they found that the condylar's structure of patients with existing TMD had remained constantly. It suggested that the subjective symptoms and clinical signs seemed to cause the subjects no or only minor problems. Among all the included studies, only studies published by Sabine Ruf et al. [50] and Laura Ivorra-Carbonell et al. [30] concerned about both healthy patients and patients with pre-existing disorders, and their designed samples included these two types of patients. And they all found that functional mandibular advancement didn't affect the normal structure of both condylar and glenoid fossa, along with condyle-glenoid fossa relationship in long-term. Laura Ivorra-Carbonell [30] summarized in their systematic review that after treatment, the position of the condylar was more forward, the glenoid fossa also remodeled and the adaption of condyle's morphology was observed, no significant adverse effect on the TMJ was observed. Sabine Ruf [50] also pointed out in their study that total disc displacement with reduction or without reduction could not be regarded as contraindications of applying functional mandibular advancement. But the researchers also indicated that for high-risk patients (patients with pathological changes in condyle), the use of such treatment should be of careful attention $[6,59]$.

\section{Limitations}

Limited high-quality RCTs were included in this study, which might lead to an inherent risk of bias. In addition, most articles didn't provide us large samples to examine, and short-time observation may also cause bias. Also too many male patients included might cause bias on results, too. More high-quality studies with low bias are recommended.

\section{Conclusions}

This study formulated a strict inclusion criterion to make the program of gathering and analyzing data more repeatable. The result of this meta-analysis performs that (1) TMJ symptoms may occur during the functional oral appliance wearing, but the symptoms will release or disappear during the follow-up period. (2) Less convincing evidence indicates that slightly pre-existing TMD will be improved after treatment. (3) There is TMJ disc anterior displacement observed during treatment, but most of them will return to the normal position later due to the remodeling of TMJ. (4) Moderate evidence support that
FMA will not induce or aggravate TMD. But gender, follow-up year, the total amount of advancement, and treatment period may affect the result to a certain extent, so a more detailed and rigorous experiment should be designed to decrease the bias from gender, follow-up year, the total amount of advancement and treatment period.

\section{Supplementary Information}

The online version contains supplementary material available at https://doi. org/10.1186/s12903-022-02075-8.

Additional file 1: Searching strategies.

Additional file 2: PRISMA flow diagram.

\section{Acknowledgements}

The authors report no commercial, proprietary, or financial interest in the products or companies described in this article.

\section{Authors' contributions}

LD and RC conducted the literature search and data extractions, LD performed the statistical analysis and draft the manuscript. LR designed the study and revised the manuscript. All authors read and approved the final version of submission.

\section{Funding}

This work was supported by grants National Natural Science Foundation of China (Nos. 81670969) and The Project of School/Hospital of Stomatology, Lanzhou University (lzukqky2020-07).

Availability of data and materials

The results of data extraction in this study are available from the corresponding author on reasonable request.

\section{Declarations}

Ethics approval and consent to participate Not applicable.

Consent for publication

Not applicable.

Competing interests

The authors declare that they have no competing interests.

Received: 13 November 2021 Accepted: 8 February 2022 Published online: 03 March 2022

\section{References}

1. Chen CM. Facial profile and frontal changes after bimaxillary surgery in patients with mandibular prognathism. J Formosan Med Assoc. 2018:7(117):632-9.

2. Lei J, Yup AUJ. Condylar repair and regeneration in adolescentsyoung adults with early-stage degenerative temporomandibular joint disease A randomised controlled study. J Oral Rehabil. 2019;46:704-14.

3. Cheib PL, et al. Displacement of the mandibular condyles immediately after herbst appliance insertion-3D assessment. Turk J Orthod. 2016:29(2):31-7.

4. Proffit WR, Fields HW. Prevalence of malocclusion and orthodontic treatment need in the United States. Int J Adult Orthodon Orthognath Surg. 1998;13(2):97-106.

5. McNamara JA Jr. Components of class II malocclusion in children 8-10years of age. Angle Orthod. 1981;51(3):177-202. 
6. Xiong $\mathrm{H}$, Hägg $\mathrm{U}$, Tang $\mathrm{GH}$. The effect of continuous bite jumping withthe Herbst appliance on the masticatorysystem a functional analysis of treated Class II malocclusions. Angle Orthod. 2004;1 (74):86-92.

7. Rabie $A B$, Xiong H, Hägg U. Forward mandibular positioning enhances condylar adaptation in adult rats. Eur J Orthod. 2004;26(Issue 4):353-8.

8. Aelbers CF, Dermaut LR. Orthopedics in orthodontics: Part I, fiction or realityma review of the literature. Am J Orthodontics Dentofacial Orthoped. 1996;110(5):513-9.

9. Santana LG, Avelar K, Flores-Mir C, Marques LS. Incremental or maximal mandibular advancement in the treatment of class II malocclusion through functional appliances: a systematic review with meta-analysis. Orthod Craniofac Res. 2020;4(23):371-84.

10. O'Reilly MT, Yanniello GJ. Mandibular growth changes and maturation of cervical vertebrae-a longitudinal cephalometric study. Angle Orthod. 1998;2(58):179-84.

11. Lars Bondemark RL. Craniomandibular status and function in patients with habitual snoring and obstructive sleep apnoea after nocturnal treatment with a mandibular advancement splint: a two-year follow-up. Eur J Orthod. 2000;22:53-60.

12. Gauer R, Semidey MJ. Diagnosis and treatment of temporomandibular disorders. Am Fam Physician. 2015;91(6):378-86.

13. Didier HA, Borromeo G, Gaffuri F. Relationship between craniofacial pain and TMD disorders an epidemiological investigation. Neurol Sci. 2018;11(39):83-4.

14. Zakrzewska JM. Differential diagnosis of facial pain and guidelines for management. Br J Anaesth. 2013;1(111):95-104.

15. Kindler S, Samietz S, Houshmand M. Depressive and anxiety symptoms as risk factors for temporomandibular joint pain a prospective cohort study in the general population. J Pain. 2012;12(13):1188-97.

16. Lim PF, Smith S, Bhalang K. Development of temporomandibular disorders is associated with greater bodily pain experience. Clin J Pain. 2010;2(26):116-20.

17. Okeson JP. Joint intracapsular disorders diagnostic and nonsurgical management considerations. Dent Clin North Am. 2007;1 (51):85-103.

18. Mohlin B, Axelsson S, Paulin G. TMD in relation to malocclusion and orthodontic treatment. Angle Orthod. 2007;3(77):542-8.

19. Keeling SD, Garvan CW, King GJ. Temporomandibular disorders after early Class II treatment with bionators and headgears results from a randomized controlled trial. Semin Orthod. 1995;3(1):149-64.

20. Wiese M, Svensson P, Bakke M. Association between temporomandibular joint symptoms, signs, and clinical diagnosis using the RDC TMD and radiographic findings in temporomandibular joint tomograms. J Orofac Pain. 2008:22:239-51.

21. Miernik M, Więckiewicze W. The Basic conservative treatment of temporomandibular joint anterior disc displacement without reduction-review. Adv Clin Exp Med. 2015;4(24):731-5.

22. Heidsieck DS, Koolstra JH. Biomechanical effects of a mandibular advancement device on the temporomandibular joint. J Craniomaxillofac Surg. 2018;2(46):288-92.

23. Tadaharu Kobayashi NITK, Isao Saito CS. Progressive condylar resorption after mandibular advancement. Br J Oral Maxillofac Surg. 2012:50:176-80

24. Jung J, Kim JH, Lee JW. Three-dimensional volumetric analysis of condylar head and glenoid cavity after mandibular advancement. J Cranio-MaxilloFacial Surg. 2018;46:1470-5.

25. Gero Kinzinger CK. Topography and morphology of the mandibular condyle during fixed functional orthopedic treatment-a magnetic resonance imaging study. J Orofac Orthop. 2007;2(68):124-47.

26. Owen AR. Unexpected TMJ responses to functional jaw orthopedic therapy. Am J Orthod Dentofacial Orthop. 1988;94(4):338-49.

27. Peltola JS, Kononen M, Nystrom M. A follow-up study of radiographic findings in the mandibular condyles of orthodontically treated patients and associations with TMD. J Dent Res. 1995;74(9):1571-6.

28. Perry HT. Adolescent temporomandibular dysfunction. Am J Orthod. 1973;63(5):517-25

29. Popowich K, Nebbe B, Major PW. Effect of Herbst treatment on temporomandibular joint morphology: a systematic literature review. Am J Orthodont Dentofacial Orthopedics. 2003;123(4)

30. Ivorra-Carbonell L, Montiel-Company JM, Almerich-Silla JM. Impact of functional mandibular advancement appliances on the temporomandibular joint—a systematic review. Med Oral Patol Oral Cir Bucal. 2016;21(5)
31. Julian PT, Higgins JTJC, Cochrane handbook for systematic reviews of interventions, 2nd edn. The Cochrane Collaboration;2019.

32. Stroup DF, Berlin JA, Morton SC. Meta-analysis of observational studies in epidemiology a proposal for reporting. Meta-analysis Of Observational Studies in Epidemiology (MOOSE) group. JAMA. 2002;15(283):2008-12.

33. Liberati A, Altman DG, Tetzlaff J. The PRISMA statement for reporting systematic reviews and meta-analyses of studies that evaluate health care interventions explanation and elaboration. Ann Internal Med. 2009:151:w65-94.

34. Sabine Ruf HP. Long-term TMJ effects of Herbst treatment: a clinical and MRI study. Am J Orthodont Dentofac Orthoped. 1998;114(5).

35. Higgins JP, Altman DG, Gøtzsche PC. The Cochrane Collaboration's tool for assessing risk of bias in randomised trials. BMJ. 2011;343:d5928

36. Popowich K, Nebbe B, Major PW. Effect of Herbst treatment on temporomandibular joint morphology a systematic literature review. Am J Orthodont Dentofacial Orthoped. 2003:4(123)

37. Ivorra-Carbonell L, Montiel-Company JM, Almerich-Silla JM. Impact of functional mandibular advancement appliances on the temporomandibular joint—a systematic review. Med Oral Patol Oral Cir Bucal. 2016:5(21):e565-72

38. Kyburz KS, Eliades T, Papageorgiou SN. What effect does functional appliance treatment have on the temporomandibular joint? A systematic review with meta-analysis. Prog Orthod. 2019;1(20)

39. Xinqi $\mathrm{H}$, Xiao C, Jun L. Meta-analysis of the condylar position changes produced by functional appliances in class II malocclusion. West China J Stomatol. 2016;6(34):589-93.

40. Armijo-Olivo S, Pitance L, Singh V. The effectiveness of manual therapy and therapeutic exercise for temporomandibular disorders a systematic review and meta-analysis. Phys Ther. 2016;96(1):9-25.

41. Owtad P, Potres Z, Shen G. A histochemical study on condylar cartilage and glenoid fossa during mandibular advancement. Angle Orthod. 2011;2(81):207-16.

42. Hansen K, Pancherz H, Petersson A. Long-term effects of the Herbst appliance on the craniomandibular system with special reference to the TMJ. Eur J Orthodont. 1990;12:244-53.

43. Cheib Vilefort PL, Farah LO. Condyle-glenoid fossa relationship after Herbst appliance treatment during two stages of craniofacial skeletal maturation: a retrospective study. Orthod Craniofac Res. 2019;22(4):345-53.

44. Näpänkangas R, Raunio A, Sipilä K. Effect of mandibular advancement device therapy on the signs and symptoms of temporomandibular disorders. J Oral Maxillofac Res. 2013:4(3):e5.

45. Xin Y, et al. MRI analysis of the effect on mandibular retrusion with anterior disc displacement treated by using Herbst appliance. Chin J Stomatol. 2017;52(3):171-5.

46. Jia W, Qiu M, Hui G. Effect of Twin-block appliance on condylar process location during mandible forward positioning: quantitative measurements. J Clin Rehabil Tissue Eng Res. 2009;13(52)

47. Kinzinger G, Gülden N, Roth A. Disc-condyle relationships during class II treatment with the functional mandibular advancer (FMA). J Orofacial Orthoped, 2006;5.

48. Kinzinger G, Gülden N, Roth A. Disc-condyle Relationships during Class II Treatment with the Functional Mandibular Advancer (FMA) Diskokondyläre Relationen bei der Therapie von Distalbisslagen mit dem Functional Mandibular Advancer (FMA). J Orofac Orthop. 2006;67(5):356-75.

49. Kinzinger GS, Lisson JA, Booth D. Are morphologic and topographic alterations of the mandibular fossa after fixed functional treatment detectable on tomograms? Visual classification and morphometric analysis. J Orofac Orthop. 2018;6(79):427-39.

50. Sabine Ruf HP. Does bite-jumping damage the TMJ a prospective longitudinal clinical and MRI study of Herbst patients. Angle Orthod. 2000;70(3):183-99.

51. Niko C, Bock SR, Long-term ( $\geq 15$ years) effects of Class II treatment a longitudinal and cross-sectional study on signs and symptoms of temporomandibular disorders. Eur J Orthodont. 2018:1-8.

52. Elfeky HY, Fayed MS, Alhammadi MS. Three-dimensional skeletal, dentoalveolar and temporomandibular joint changes produced by Twin Block functional appliance. J Orofac Orthop. 2018;4(79):245-58.

53. Bueno CH, Pereira DD, Pattussi MP. Gender differences in temporomandibular disorders in adult populational studies A systematic review and meta-analysis. J Oral Rehabil. 2018;45(9):720-9. 
54. Sójka A, Stelcer B, Roy M. Is there a relationship between psychological factors and TMD? Brain Behavior. 2019;9:e01360.

55. Kim TY, Shin JS, Lee J. Gender difference in associations between chronic temporomandibular disorders and general quality of life in Koreans a cross-sectional study. PLoS One. 2015;

56. Knappe SW, et al. Long-term side effects on the temporomandibular joints and oro-facial function in patients with obstructive sleep apnoea treated with a mandibular advancement device. J Oral Rehabil. 2017:44:354-62.

57. Valladares-Neto J, et al. TMJ response to mandibular advancement surgery: an overview of risk factors. J Appl Oral Sci. 2014;22(1):2-14

58. Chen HM, Liu MQ. Physiological effects of anterior repositioning splint on temporomandibular joint disc displacement a quantitative analysis. J Oral Rehabil. 2017:44(9):664-72.

59. Perez $\mathrm{CV}$, de Leeuw R. The incidence and prevalence of temporomandibular disorders and posterior open bite in patients receiving mandibular advancement device therapy for obstructive sleep apnea. Sleep Breath. 2013:17:323-32

\section{Publisher's Note}

Springer Nature remains neutral with regard to jurisdictional claims in published maps and institutional affiliations.

- fast, convenient online submission

- thorough peer review by experienced researchers in your field

- rapid publication on acceptance

- support for research data, including large and complex data types

- gold Open Access which fosters wider collaboration and increased citations

- maximum visibility for your research: over $100 \mathrm{M}$ website views per year

At BMC, research is always in progress.

Learn more biomedcentral.com/submissions 